\title{
Efeito do clareamento de dentes afetados por tetraciclina: relato de caso clínico
}

\begin{abstract}
- André Marcelo Peruchi Minto Departamento de Dentística, Universidade de Franca, Franca, SP, Brasil • Carla Larissa Vidal Departamento de Materiais Dentários e Prótese, Faculdade de Odontologia de Ribeirão Preto, Universidade de São Paulo, Ribeirão Preto, SP, Brasil • Andréa Cândido dos Reis Departamento de Materiais Dentários e Prótese, Faculdade de Odontologia de Ribeirão Preto, Universidade de São Paulo, Ribeirão Preto, SP, Brasil
\end{abstract}

RESUMO | Introdução: O clareamento de dentes manchados por tetraciclina é desafiador. Este artigo relata um caso clínico de clareamento de dentes manchados em decorrência do uso de tetraciclina, apresentando-se no grau 2. Materiais e métodos: O clareamento foi feito com peróxido de hidrogênio 37,5\% (Pola Office Plus - SDI Southern Dental Industries, Bayswater, VIC, Austrália), realizado em seis sessões de três aplicações do produto por oito minutos. O paciente foi acompanhado por seis meses. Resultados: Após as aplicações do agente clareador, a técnica e o material selecionado promoveram significativa redução do escurecimento generalizado dos dentes. A área cervical, onde estavam concentradas as manchas acastanhadas, apresentou evidente clareamento. Conclusão: O clareamento dentário como tratamento de manchas induzidas por tetraciclina apresenta-se como uma opção eficaz e conservadora.

DESCRITORES | Clareamento Dental; Tetraciclinas; Peróxido de Hidrogênio.

ABSTRACT | Effect of whitening of teeth affected by tetracycline: clinical case report - Introduction: The whitening of tetracycline-stained teeth is challenging. This article reports a clinical case of a whitening process of stained teeth in second degree due to the use of tetracycline. Materials and methods: Whitening was performed using 37.5\% hydrogen peroxide (Pola Office Plus - SDI Southern Dental Industries, Bayswater, VIC, Australia), conducted in six sessions of three applications of the product for eight minutes. The patient had a follow-up for six months. Results: After applications of the bleaching agent, the selected technique and material promoted a significant reduction of the generalized discolorations of the teeth. The cervical area, where the brownish spots were concentrated, showed evident whitening. Conclusion: Dental whitening as a treatment for tetracycline-induced discolorations is an effective and conservative option.

DESCRIPTORS | Tooth Whitening; Tetracyclines; Hydrogen Peroxide.

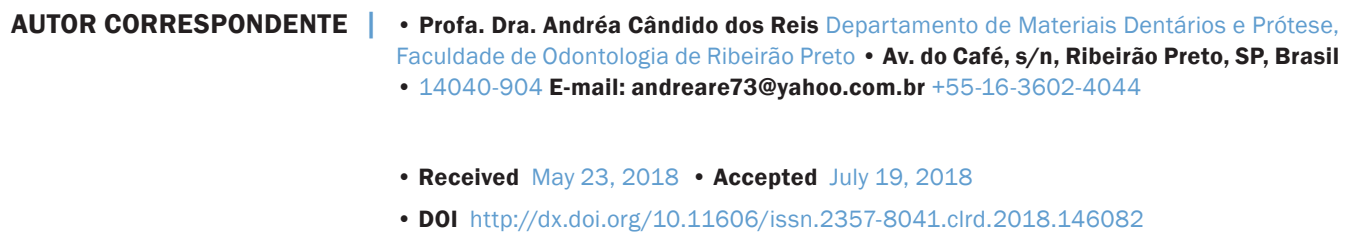




\section{INTRODUÇÃO}

As tetraciclinas apresentam grande amplitude para uso clínico contra diversas infecções, devido ao seu amplo espectro de atividade antimicrobiana. Seu uso tem sido restrito à terapia combinada para metástase óssea, profilaxia da tuberculose, antraz, malária e acne em adolescentes e adultos jovens, devido à resistência bacteriana. ${ }^{1} \mathrm{~A}$ tetraciclina é considerada agente teratogênico e possui efeitos colaterais: um deles é o manchamento de dentes. ${ }^{2-5}$

O manchamento dental causado pelo uso da tetraciclina depende da dose administrada, duração do tratamento e estágio do desenvolvimento dentário. ${ }^{2,4,5}$ Isso ocorre devido à capacidade de formar um complexo com íons de cálcio, chamado de quelação. ${ }^{6}$ Esse processo se dá entre a tetraciclina e íons de cálcio para formar complexos estáveis de ortofosfato de cálcio e tetraciclina, que são depositados nos ossos e dentes, sendo a dentina mais suscetível do que o esmalte. ${ }^{7}$

O manchamento induzido pela tetraciclina é considerado permanente, uma vez que a dentina e o esmalte não podem ser remodelados. A coloração varia de amarelo ou cinza a marrom com ou sem faixas. ${ }^{6} \mathrm{O}$ manchamento cinza-marrom se origina da clorotetraciclina, enquanto a tetraciclina e a dimetilclorotetraciclina causam manchamento amarelo, e a oxitetraciclina causa colorações menos intensas. ${ }^{8}$

A tetraciclina deve ser evitada em gestantes durante o segundo e terceiro trimestres da gravidez e em crianças até os oito anos de idade, ${ }^{6}$ pois a calcificação da dentição decídua começa no final do quarto mês de gestação e continua até os 1114 meses de idade após período uterino, e a da dentição permanente se inicia após o nascimento, continuando sua calcificação até os oito anos de idade. A coloração ocorre com mais frequência na dentição em desenvolvimento quando a dosagem total é superior a 3g, ou a administração excede 10 dias. $^{9}$
O manchamento induzido pela tetraciclina é classificado em quatro graus: 1) o primeiro é a coloração leve, que varia de amarelo a cinza, sem faixas; 2) o segundo, coloração moderada variando de amarelo-acastanhada a cinza-escura; 3) o terceiro, coloração severa que varia de cinza-azulado ou preto com faixas significativas no dente; 4) e o quarto grau é estendido e apresenta coloração mais severa. ${ }^{1}$

O tratamento para esse tipo de manchamento dental inclui clareamento, ${ }^{9}$ preparo dental seguido por restauração com resina composta, laminado ${ }^{10}$ ou metalocerâmica com cobertura total ou coroas cerâmicas totais para melhorar a aparência estética. O clareamento é a opção mais conservadora, sem desgaste de substrato dental sadio, além de promover melhor satisfação e qualidade de vida. ${ }^{11,12}$

Sistemas de clareamento dental à base de peróxido de carbamida e peróxido de hidrogênio têm sido clinicamente seguros, sem efeitos colaterais irreversíveis e com custo biológico mínimo ao esmalte dental, onde são observadas alterações mínimas ou ausentes em substratos dentinários e de esmalte. ${ }^{10,13,14}$ A utilização de agentes clareadores não causa desmineralização do esmalte, ${ }^{15}$ nem alteração na sua microdureza de superfície. ${ }^{16}$

Um efeito colateral comum é a sensibilidade térmica de dentes individuais, que pode ocorrer durante o procedimento de clareamento ${ }^{13,17} \mathrm{e}$, geralmente, cessa com sua suspensão. ${ }^{13}$ Danos biológicos podem ocorrer, como irritação gengival por agentes clareadores, que pode ser evitada aplicandose, quando em consultório, uma barreira gengival e pela utilização de moldeira individual adequada, quando pela técnica caseira. Assim, o agente clareador tem contato mínimo com o tecido mole. ${ }^{13}$

Quando utilizado de forma indiscriminada, o peróxido de hidrogênio liberado dos agentes clareadores pode se difundir através do esmalte e da dentina e penetrar na câmara pulpar, onde pode reduzir a proliferação, o metabolismo e a viabilidade celular, o que pode levar à necrose tecidual. ${ }^{17-19}$ 
Porém, extensões citoplasmáticas odontoblásticas, líquido dentinário e enzimas que degradam peróxido de hidrogênio protegem a polpa de efeitos citotóxicos de agentes clareadores por impedir ou dificultar sua penetração por túbulos dentinários, no caso de dentes polpados. ${ }^{20}$

Após a aplicação dos sistemas de clareamento à base de peróxido, os anéis de quinona nas tetraciclinas, responsáveis pela coloração vermelha, podem ser alterados para moléculas menos coloridas, ${ }^{21} \mathrm{o}$ que alivia a aparência do manchamento quando usado por longos períodos. Gel de peróxido de carbamida a 10\% também apresenta efeito com duração de até 90 meses. ${ }^{22} \mathrm{~A}$ combinação de um tratamento controlado com peróxido de hidrogênio a $6 \%$ e peróxido de carbamida a $15 \%$ mostraram eficácia no clareamento de dentes manchados por tetraciclina. ${ }^{10}$

Este estudo relata um caso clínico de clareamento de dentes manchados por tetraciclina, utilizando peróxido de hidrogênio $37,5 \%$.

\section{RELATO DO CASO CLÍNICO}

Paciente do sexo feminino, com 26 anos de idade, procurou tratamento odontológico. Durante o exame clínico, foram encontradas manchas de coloração acastanhada na vestibular dos dentes anteriores superiores e inferiores, com maior concentração no terço médio a gengival. Durante a anamnese, a paciente relatou o uso do antibiótico tetraciclina durante a infância. Após anamnese e exame clínico, pôde-se identificar que as manchas nos dentes foram ocasionadas devido à ingestão pregressa de tetraciclina. Foi proposto o tratamento clareador para a eliminação das manchas, caracterizadas por pigmentação moderada de coloração castanha, com maior concentração na área cervical dos dentes anteriores superiores (Figura 1). A paciente concordou e autorizou a publicação das informações referentes ao seu caso clínico.

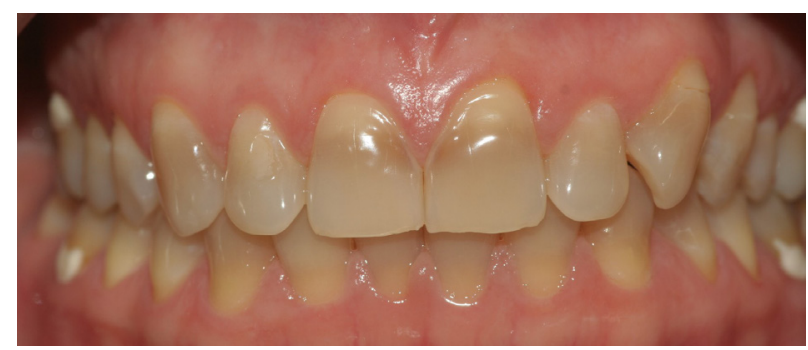

Figura 1 | Foto inicial do caso

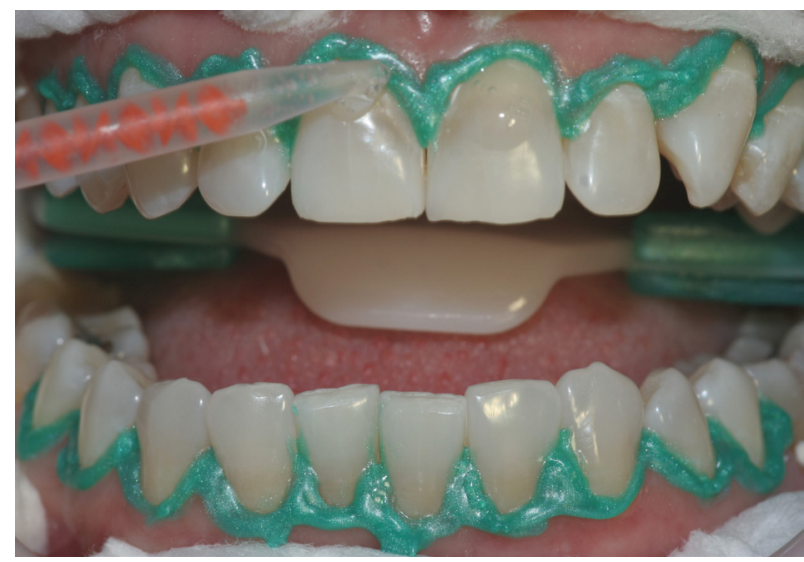

Figura 2 | Aplicação da barreira gengival fotoativada

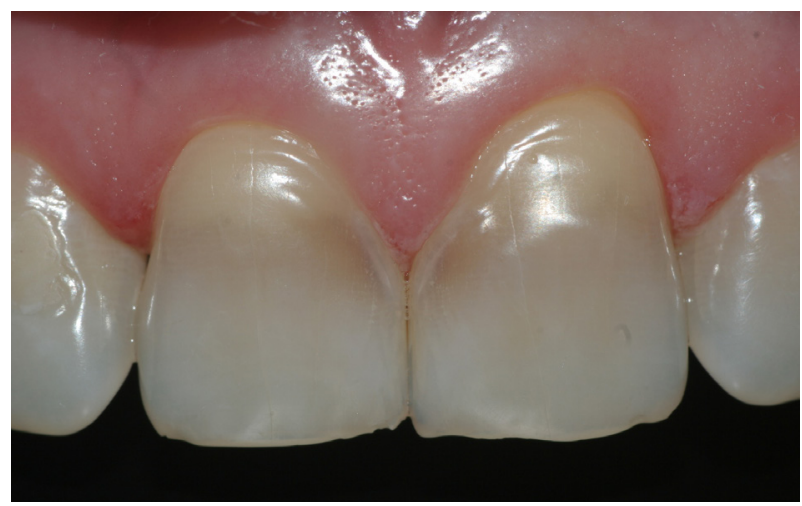

Figura 3 | Elementos 11 e 21 com desgaste erosivo na região cervical vestibular.

Para o tratamento clareador, utilizou-se o clareador Pola Office Plus (SDI Southern Dental Industries, Bayswater, VIC, Austrália) cujo agente clareador corresponde ao peróxido de hidrogênio na concentração de $37,5 \%$. Optou-se pelo clareamento de consultório para que o profissional tivesse total controle e supervisão do tratamento, uma vez que o paciente apresentava lesões erosivas nos elementos dentais (Figura 3). Esse processo de clareamento 
foi selecionado pois o fabricante afirma que o produto é um gel à base de peróxido de hidrogênio, com pH neutro, e que contém dessensibilizantes que maximizam o conforto do paciente. $O$ produto apresenta, na sua composição, hidróxido de sódio como dessensibilizante, e não há necessidade de fotoativação, de acordo com o fabricante. Realizaram-se seis sessões, nas quais foram feitas quatro aplicações do produto por oito minutos em consultório, com intervalo de quinze dias entre sessões. Em todas as aplicações, foi colocada barreira gengival do kit clareador Pola Office Plus, completamente fotoativada (Figura 2).

Devido à presença de desgaste erosivo cervical nos elementos 11 e 21 (Figura 3), a paciente relatava hipersensibilidade na região vestibular. Para reduzir essa hipersensibilidade, aplicou-se o sistema adesivo $^{23}$ (Single Bond Universal, 3M ESPE, EUA) (Figura 4), com prévio tratamento condicionador com ácido fosfórico a 37\% (Figura 5) durante 30 segundos, apenas na cervical, para que houvesse uma proteção do complexo dentinopulpar durante o tratamento clareador. Além disso, em todas as sessões, foi realizada a aplicação tópica de flúor pósclareamento dental.

A conferência do resultado foi feita por meio da comparação inicial e final de tomada de cor utilizando-se a escala Vita Classic (Vita, Zahnfabrik, Säckingen, Alemanha). Inicialmente, os dentes apresentavam três faixas de tons, sendo elas $\mathrm{C}_{4}, \mathrm{C}_{3}$ e C2, no sentido cervical em direção ao incisal. O resultado (Figura 6) demonstrou, em todos os elementos anteriores, significativa redução da manchas acastanhadas, com elementos apresentando-se na cor C2 na cervical e C1 na incisal, de acordo com a escala Vita. Após o tratamento clareador, a cervical vestibular dos elementos $11 \mathrm{e}$ 21 foi restaurada com resina flow (Filtek Supreme Plus, 3M ESPE, EUA), para sua proteção. Houve acompanhamento por seis meses e o resultado obtido pelo tratamento clareador se manteve.

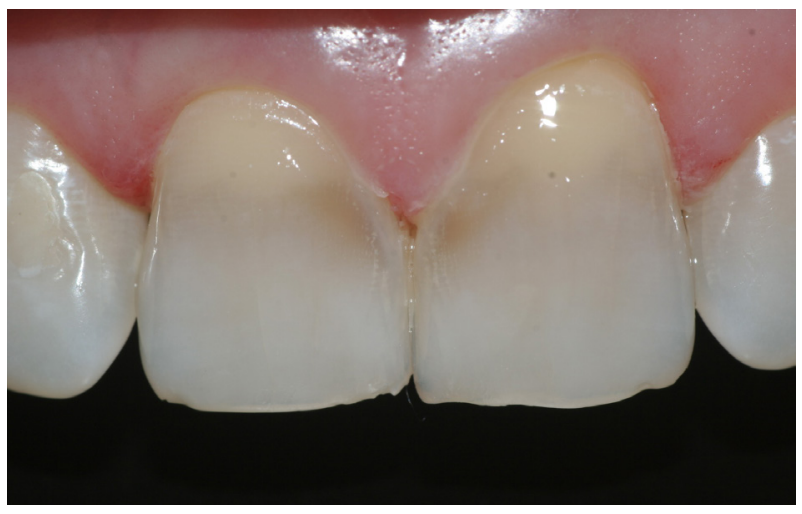

Figura 4 | Elementos 11 e 21 protegidos sistema adesivo.

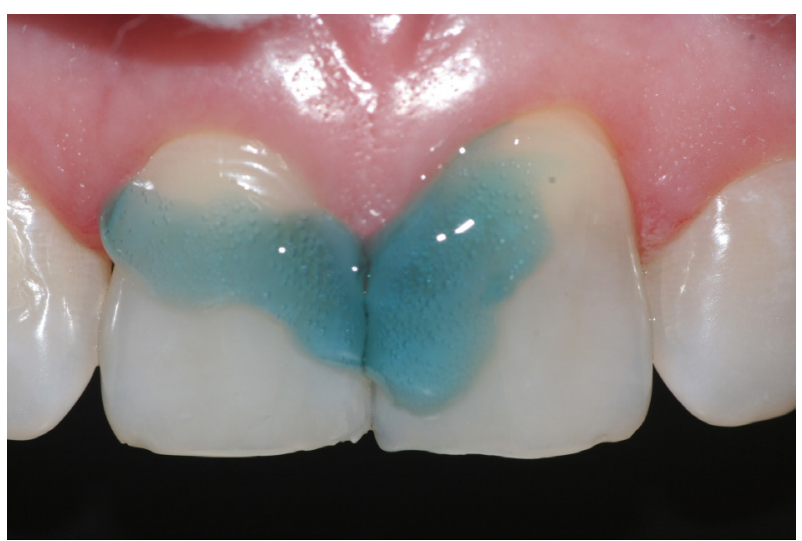

Figura 5 | Tratamento ácido nos elementos 11 e 21.

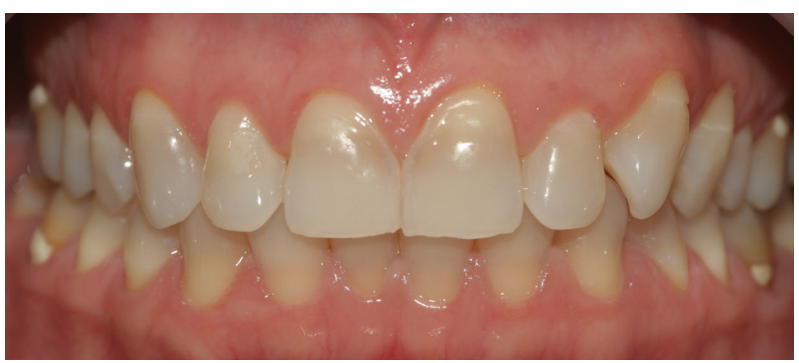

Figura 6 | Foto final do caso após 6 sessões de clareamento

\section{DISCUSSÃO}

Manchas causadas por tetraciclina podem ser removidas com muito sucesso por clareamento, sendo mais difíceis de remover as localizadas em áreas cervicais. O prognóstico não é dependente somente da gravidade do manchamento, mas também de sua localização. ${ }^{10,24,25}$

Neste caso, a paciente apresentava manchamento induzido por tetraciclina de grau 2, com manchas 
amarelo-acastanhadas concentradas na região cervical dos dentes anteriores superiores, além de um grau de escurecimento generalizado nas coroas clínicas dentais. O manchamento acentuado no terço gengival oferece prognóstico ruim para a intervenção com clareamento. ${ }^{22}$ Apesar disso, houve resultado satisfatório com esse tratamento.

A forma mais conservadora de modificar a coloração dental é por meio do clareamento. ${ }^{26}$ Géis destinados a essa finalidade contêm peróxido de hidrogênio ou seu precursor, peróxido de carbamida, como ingrediente ativo em concentrações que variam de $3 \%$ a $40 \% .{ }^{27}$ No caso descrito, pelo fato de a paciente apresentar sensibilidade e erosão, optou-se pelo clareamento de consultório para que houvesse supervisão direta do profissional a todo momento, bem como a proteção das áreas erodidas e aplicação rigorosa e controlada de flúor.

O peróxido de hidrogênio é um agente oxidante que, ao se difundir no dente, dissociase para produzir radicais livres instáveis de hidroxila, peridroxila, ânions peridroxila e ânions superóxido, que atuará sobre moléculas orgânicas pigmentadas nos espaços entre os sais inorgânicos no esmalte dentário, atacando as ligações duplas de moléculas cromóforas dentro dos tecidos dentais. ${ }^{27,28}$ Isso resulta em constituintes menores, com pigmentação menos forte, e haverá uma mudança no espectro de absorção das moléculas de cromóforos. ${ }^{28}$

No caso de dentes manchados por tetraciclina, a causa do manchamento é derivada da foto-oxidação de moléculas de tetraciclina disponíveis dentro das estruturas dentárias. $\mathrm{O}$ mecanismo de clareamento, nesse caso, ocorre pela degradação química de estruturas do tipo quinona insaturadas encontradas na tetraciclina, levando a um menor número de moléculas coloridas. ${ }^{27}$

No caso relatado, a aplicação do agente clareador peróxido de hidrogênio a 37,5\%, durante seis sessões (quatro aplicações de oito minutos por sessão) foi capaz de reduzir significativamente a intensidade do manchamento acastanhado devido à ingestão de tetraciclina. Esse achado corrobora com o estudo de Matis et al. ${ }^{29}$, em que, na avaliação profissional, 90\% dos dentes foram considerados com resultado estético excelente ou satisfatório, após o clareamento com 10\%, 15\% e 20\% de peróxido de carbamida, sendo este considerado efetivo na remoção de manchas causadas pela tetraciclina ${ }^{29}$, assim como o peróxido de hidrogênio. ${ }^{30}$

Apesar da eficácia desse tipo de tratamento com pelo menos 30\% de reversão de cor, recomenda-se novo clareamento após quatro ou cinco anos para obter a máxima luminosidade do dente. ${ }^{28}$ É importante informar ao paciente da possibilidade de aumento da sensibilidade dentária em tratamentos com concentrações elevadas de agente clareador. ${ }^{24}$

Neste caso clínico, aplicou-se o sistema adesivo para promover a diminuição da sensibilidade dentinária. Erdemir et al. ${ }^{23}$ afirma que adesivos são comumente usados para esse fim, pois criam uma camada híbrida sobre a dentina, bloqueando o estímulo da dor que afeta diretamente o tecido pulpar. Os adesivos desnaturam proteínas dentinárias e, consequentemente, reduzem a permeabilidade dentinária. ${ }^{23}$

No caso aqui estudado, o tratamento clareador apresentou resposta satisfatória, porém é necessário enfatizar que na maioria dos casos de dentes corados com tetraciclina, as áreas cervicais são mais difíceis de serem clareadas. ${ }^{24}$

\section{CONCLUSÃO}

O tratamento de manchas induzidas por tetraciclina grau 2 por meio do clareamento dental por peróxido de hidrogênio a 37,5\% mostrou-se efetivo, sendo essa uma opção conservadora e viável. 


\section{REFERÊNCIAS}

1. Newsome PR, Linda H. Management of tetracycline discoloured teeth. Aes Dent Today. 2008;2(6):15-20.

2. Cohlan SQ. Tetracycline staining of teeth. Teratology, 1977;15(1):127-9.

3. Watts A, Addy M. Tooth discolouration and staining: a review of the literature. Br Dent J. 2001;190(6):309.

4. Vennila V, Madhu V, Rajesh R, Ealla KKR, Velidandla SR, Santoshi S. Tetracycline-induced discoloration of deciduous teeth: case series. J Int Oral Health. 2001;6(3):115-9.

5. Long SS. Optimizing antimicrobial therapy in children. J Infect. 2016;72: S91-7.

6. Sanchez AR, Rogers RS, Sheridan PJ. Tetracycline and other tetracycline-derivative staining of the teeth and oral cavity. Int J Dermatol. 2004;43(10):709-15.

7. Wallman IS, Hilton HB. Teeth pigmented by tetracycline. Lancet. 1962;1(7234):827-9.

8. Eisenberg E. Anomalies of the teeth with stains and discolorations. J Prev Dent. 1975;2(1):7-14.

9. Tredwin CJ, Scully C, Bagan-Sebastian JV. Drug-induced disorders of teeth. J Dent Res. 2005;84(7):596-602.

10. Botelho MG, Chan AWK, Newsome PRH, McGrath CP, Lam WYH. A randomized controlled trial of home bleaching of tetracycline-stained teeth. J Dent. 2017;67:29-35.

11. Meireles SS, Goettems ML, Dantas RVF, Della Bona A, Santos IS, Demarco FF. Changes in oral health related quality of life after dental bleaching in a double-blind randomized clinical trial. J Dent. 2014;42(2):114-121.

12. Martin J, Vildosola P, Bersezio C, Herrera A, Bortolatto J, Saad JRC, et al. Effectiveness of 6\% hydrogen peroxide concentration for tooth bleaching: a double-blind, randomized clinical trial. J Dent. 2015;43(8):965-72.

13. Auschill TM, Hellwig E, Schmidale S, Sculean A, Arweiler NB. Efficacy, side-effects and patients' acceptance of different bleaching techniques (OTC, in-office, at-home). Oper Dent. 2005;30(2):156-63.

14. Leonard RHJR. Efficacy, longevity, side effects, and patient perceptions of nightguard vital bleaching. Compend Contin Educ Dent. 1998;19(8):766-70.

15. Moreira RF, Santos FP, Santos EA, Santos RSD, Anjos MJD, Miranda MSD. Analysis of the chemical modification of dental enamel submitted to $35 \%$ hydrogen peroxide "InOffice" whitening, with or without calcium. Int J Dent. 2017;2017:4646789.
16. Mansouri RS, Khzam N. Hydrogen peroxide tooth whitening agent effect on the nanomechanical properties of enamel. J Res Med Dent Sci. 2017;5(2):91-101.

17. Lima SNL, Ribeiro IS, Grisotto MA, Fernandes ES, Hass V, de Jesus Tavarez RR, et al. Evaluation of several clinical parameters after bleaching with hydrogen peroxide at different concentrations: a randomized clinical trial. J Dent. 2018;68:91-7.

18. Cintra LTA, Benetti F, da Silva Facundo AC, Ferreira LL, Gomes-Filho JE, Ervolino E, et al. The number of bleaching sessions influences pulp tissue damage in rat teeth. J Endod. 2013;39(12):1576-80.

19. Kwon SR, Li Y, Oyoyo U, Aprecio RM. Dynamic model of hydrogen peroxide diffusion kinetics into the pulp cavity. $J$ Contemp Dent Pract. 2012;13(4):440-5.

20. Soares DG, Ribeiro APD, da Silveira Vargas F, Hebling J, de Souza Costa CA. Efficacy and cytotoxicity of a bleaching gel after short application times on dental enamel. Clin Oral Investig. 2013;17(8):1901-9.

21. Joiner A. The bleaching of teeth: a review of the literature. J Dent. 2006;34(7):412-9.

22. Leonard RH, Haywood VB, Caplan DJ, Tart ND. Nightguard vital bleaching of tetracycline-stained teeth: 90 months post treatment. J Esthet Restor Dent. 2003;15(3):142-53.

23. Erdemir U, Saygi G, Yucel T, Yildiz E. Dentin hypersensitivity and recent developments in treatment options: a mini review. Dent. 2016;4(4):1072.

24. Matis BA, Wang Y, Eckert GJ, Cochran MA, Jiang T. Extended bleaching of tetracycline-stained teeth: a 5-year study. Oper Dent. 2006;31(6):643-51.

25. Haywood VB, Pohjala R. Bleaching and esthetic bonding of tetracycline-stained teeth. Cont Esthet Rest Dent. 2004;7:16-23.

26. Carey CM. Tooth whitening: what we now know. J Evid Based Dent Pract. 2014;14:70-6.

27. Alqahtani MQ. Tooth-bleaching procedures and their controversial effects: a literature review. Saudi Dent J. 2014;26(2):33-46.

28. Minoux M, Serfaty R. Vital tooth bleaching: biologic adverse effects - a review. Quintessence Int. 2008;39(8):645-59.

29. Matis BA, Wang Y, Jiang T, Eckert GJ. Extended at-home bleaching of tetracycline-stained teeth with different concentrations of carbamide peroxide. Quintessence Int. 2002;33(9):645-55.

30. Joiner A. The bleaching of teeth: a review of the literature. J Dent. 2006;34(7):412-9. 